\title{
Investigation of Radiation Energy Balance in Some Selected Cities in Nigeria.
}

\author{
Isikwue, B. C. ${ }^{1 *}$, Akiishi ${ }^{1}$, M. And Utah, E. $U^{2}$. \\ ${ }^{1}$ Department of Physics, Federal University of Agriculture Makurdi, Benue State, Nigeria. \\ ${ }^{2}$ Department of Physics, University of Uyo, Uyo - Nigeria.
}

\begin{abstract}
The evaluations of radiation energy balance are hereby present some selected cities in the tropical forest and savannah zones of Nigeria. The data used for the study were obtained from the Nigerian Meteorological Agency (NIMET) Abuja, (1990-2010). The results among other things show that the albedo was generally high (60 to 64\%), in all the locations considered, implying that majority of the solar radiation in these locations did not reach the surface. However, there are increases in the radiation balance in Port Harcourt and Makurdi locations, whereas in Enugu and Kano, the curves indicate negative or decrease in radiation balance. This implies that there is a balance in solar energy radiation budget that could enhance solar energy technologies in Port Harcourt and Makurdi towns. On the other hand, suggestions have been made on the need for seasonal considerations of the radiation balance for more efficient climatic and solar technological planning.
\end{abstract}

Keywords: albedo, Net solar radiation, Net terrestrial radiation, Radiation balance, Solar radiation,

\section{Introduction}

The energy that drives the climate system comes from the sun. However, not all of the sun's energy comes to Earth. The sun's energy is emitted in all directions, with only a small fraction being in the direction of the Earth. The Earth's climate system constantly adjusts in a way that tends toward maintaining a balance between the energy that reaches the Earth from the sun and the energy that goes from Earth back to space. Some anthropogenic perturbations contribute to a positive radiative forcing which reduces the net long wave radiation loss out to space, thus, the radiation balance is disturbed, which in turn causes a change in the Earth's energy.

Some research works on the estimation and utilization of solar radiation have been carried out in Nigeria, especially, in the savannah ecological zone of the country ([1]; [2] and [3 -8]). However, none of these works has estimated the radiation balance of the atmosphere over the locations considered in this work). The locations considered are Port Harcourt, Enugu and Makurdi and Kano. These cities were chosen because of their industrial and climatic features, which may influence the radiation budget of the cities.

Port Harcourt in the tropical forest zone is an industrial area. Thus, there could be possible sites of solar energy based technology industries. Its coastal location at the bank of the Atlantic Ocean may also have effect on the radiation balance. Enugu and Makurdi are in the guinea savannah ecological zone of the country. Enugu is flanked with hills and valleys and is the coal base of Nigeria. It is also gradually getting industrialized. Hence, there could be need to ascertain the radiation energy balance in the area. Makurdi, in the north central region of the country is noted for its high temperature due the presence of the River Benue, which cuts across the city and serves as a heat reservoir. This could affect the energy balance in the area.

Kano, being in the Sudan - Sahelian zone with its proximity to the Sahara desert influence could serve as a good object of study with respect to energy radiation balance. It is also important to note that it has not been found in the literature where the energy radiation balance in these cities was considered.

The daily global solar radiation, minimum temperature and maximum temperature data used in this work were obtained from the Nigeria Meteorological Agency (NIMET) Abuja - Nigeria (1990 - 2010). The solar radiation parameters considered in this work are the global solar radiation denoted by SR, the net solar radiation (NSR), the reflection coefficient (RC) or albedo denoted by $\mathrm{Hr} / \mathrm{Ra}$, the net terrestrial radiation (NTR) and the radiation balance $(\mathrm{RB})$.

\section{Methods}

The net solar radiation NSR $\left(\mathrm{MJm}^{-2} \mathrm{day}^{-1}\right)$ was determined using the equation given by [9] as

$$
\mathrm{NSR}=\mathrm{R}_{\mathrm{s}}\left(1-\alpha_{\mathrm{s}}\right) \text {, }
$$

$R_{\mathrm{s}}$ is the global solar radiation, $\alpha_{\mathrm{s}}$ is the albedo of the location obtained from [7] as

$$
\alpha_{\mathrm{s}}=\frac{\mathrm{H}_{\mathrm{r}}}{\mathrm{R}_{\mathrm{a}}}
$$

and the $\mathrm{H}_{\mathrm{r}}$ is the reflected radiation given as

$$
H_{r}=\left(1-\frac{R_{s}}{R_{a}}\right) R_{a},
$$


$\mathrm{R}_{\mathrm{a}}$ is the extraterrestrial radiation obtained using [3].

Furthermore, the net terrestrial radiation was obtained using the expression [9]:

$$
\mathrm{NTR}=\mathrm{S}\left[\frac{\mathrm{T}^{4}{ }_{\max }+\mathrm{T}^{4}{ }_{\min }}{2}\right]\left(0.34-0.14 \sqrt{\mathrm{e}_{\mathrm{a}}}\right)\left(1.35 \times \frac{\mathrm{R}_{\mathrm{S}}}{\mathrm{R}_{\mathrm{so}}}-0.35\right)
$$

$\mathrm{T}_{\max }, \mathrm{T}_{\min }, \mathrm{R}_{\mathrm{s}}, \mathrm{S}$ are maximum temperature, minimum temperature, global solar radiation and the Stefan Boltzmann's constant respectively. The actual vapour pressure, $e_{a}$, was computed using the relation adapted from [10] as:

$$
\mathrm{e}_{\mathrm{a}}=0.611 \exp \left[\frac{17.27 \mathrm{~T}_{\min }}{\mathrm{T}_{\min }+273.3}\right]
$$

On the other hand, the clear sky solar radiation $\left(\mathrm{MJm}^{-2} \mathrm{day}^{-1}\right), \mathrm{R}_{\mathrm{so}}$ was obtained using the [11]:

$$
R_{\text {so }}=\left(0.75+2 \times 10^{-5} \times Z\right) R_{a}
$$

where

$\mathrm{Z}$ is the elevation of the station above sea level (m). For Makurdi, PortHarcourt, Enugu, Oyo, and Kano, the values for $Z$ are about $106.4,468,248,287$ and $479 \mathrm{~m}$ respectively.

Finally, the radiation balance, RB of the Earth-atmosphere over Makurdi was determined by subtracting net terrestrial radiation from net solar radiation thus:

$$
\mathrm{RB}=\mathrm{R}_{\mathrm{s}}\left(1-\alpha_{\mathrm{s}}\right)-\mathrm{S}\left[\frac{\mathrm{T}^{4}{ }_{\mathrm{max}}+\mathrm{T}^{4}{ }_{\min }}{2}\right]\left(0.34-0.14 \sqrt{\mathrm{e}_{\mathrm{a}}}\right)\left(1.35 \times \frac{\mathrm{R}_{\mathrm{s}}}{\mathrm{R}_{\mathrm{so}}}-0.35\right)
$$

\section{Results And Discussion}

Figures $1-4$ show the temporal variations of SR, NSR, RC, NTR and RB in Port Harcourt, Enugu, Makurdi and Kano respectively; while the maximum and minimum values of these parameters in these locations are presented in Table 1.
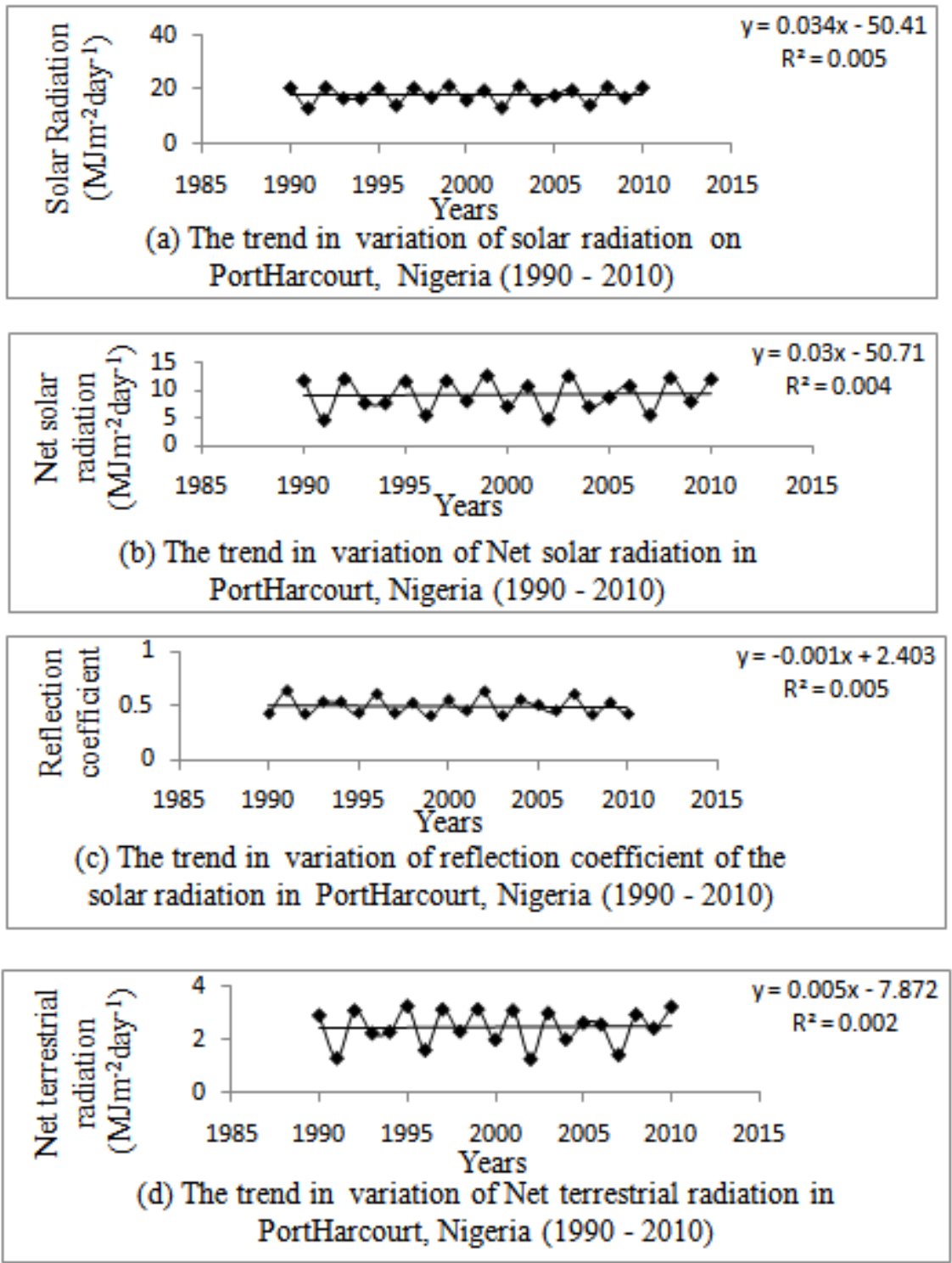


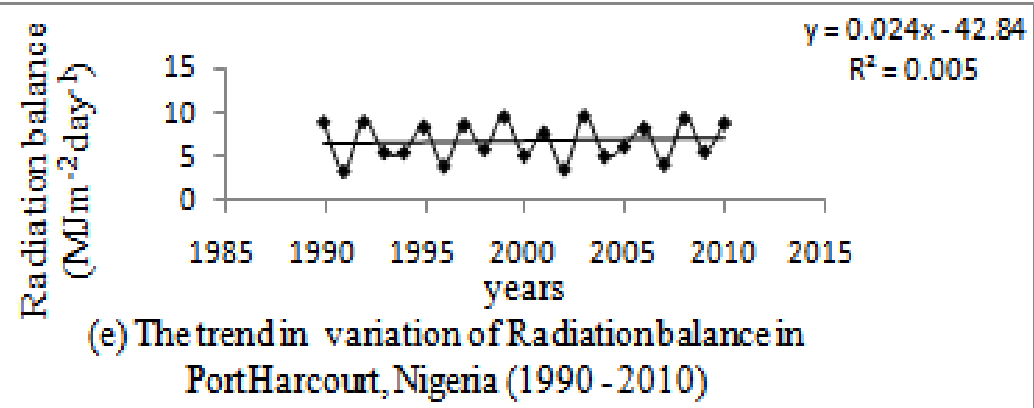

Fig. 1: Temporal variations of solar radiation parameters in Port Harcourt, Nigeria (1990 - 2010)
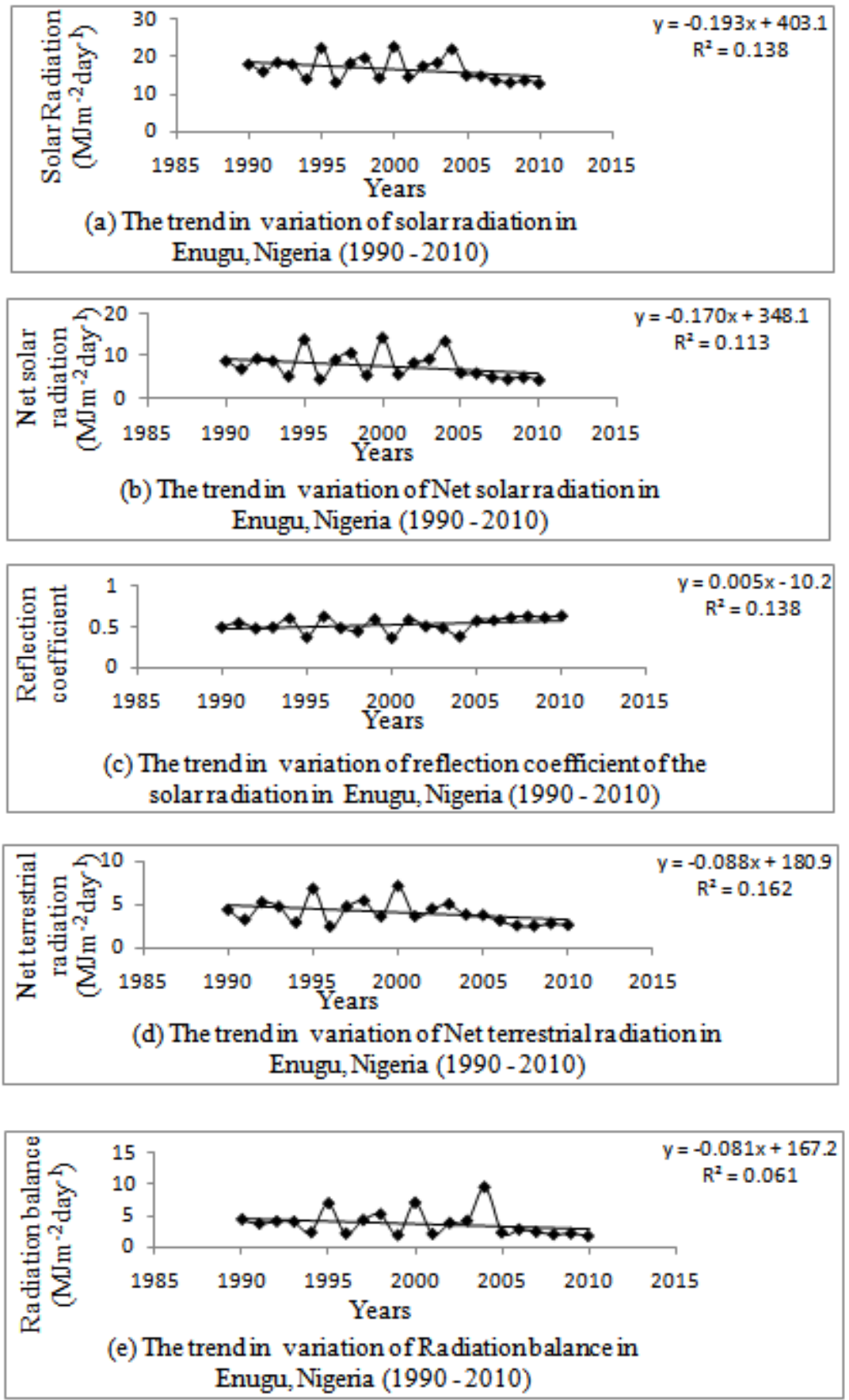

Fig. 2: Temporal variations of solar radiation parameters in Enugu, Nigeria (1990 - 2010) 


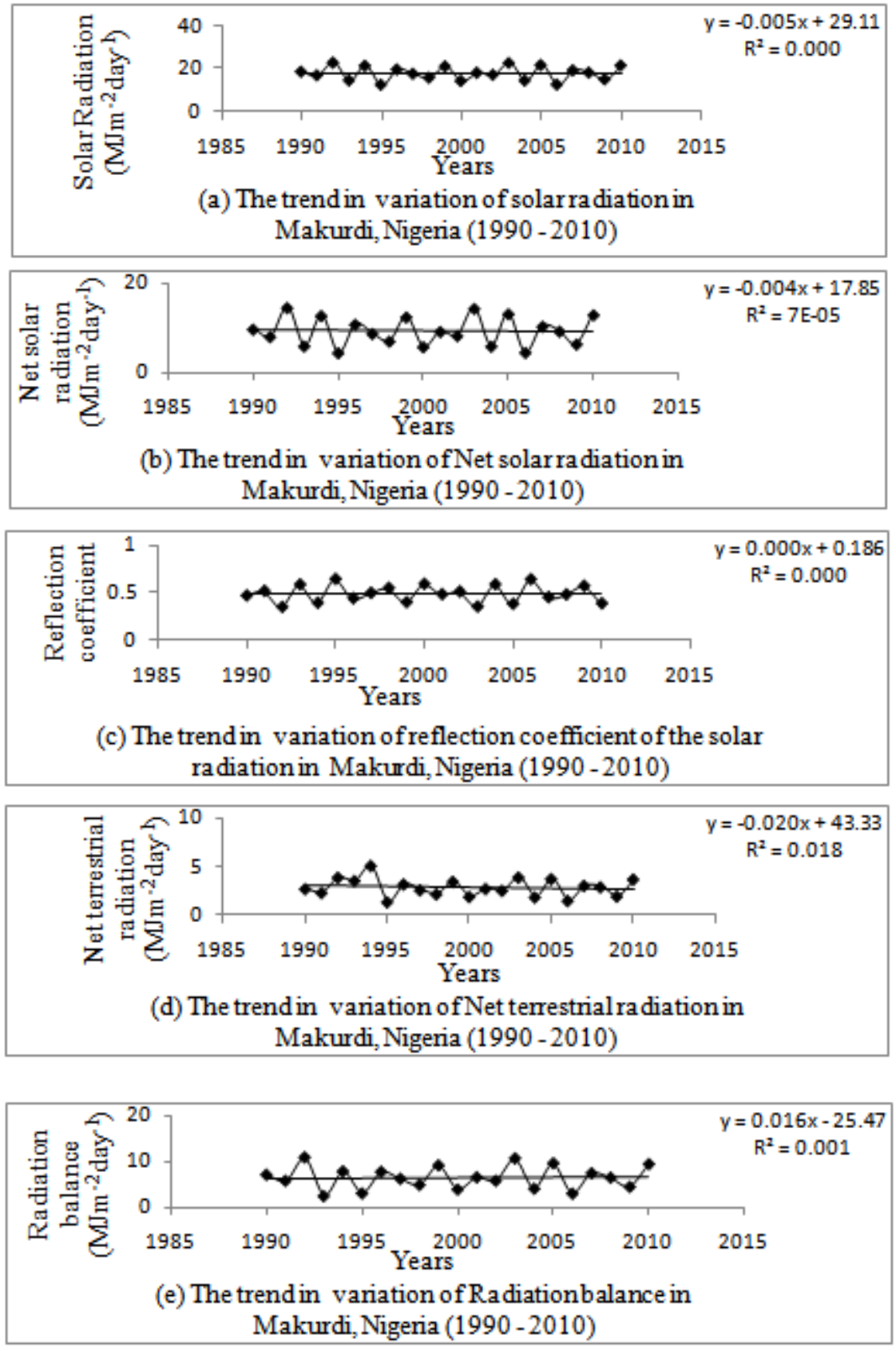

Fig. 3: Temporal variations of solar radiation parameters in Makurdi, Nigeria (1990 - 2010)

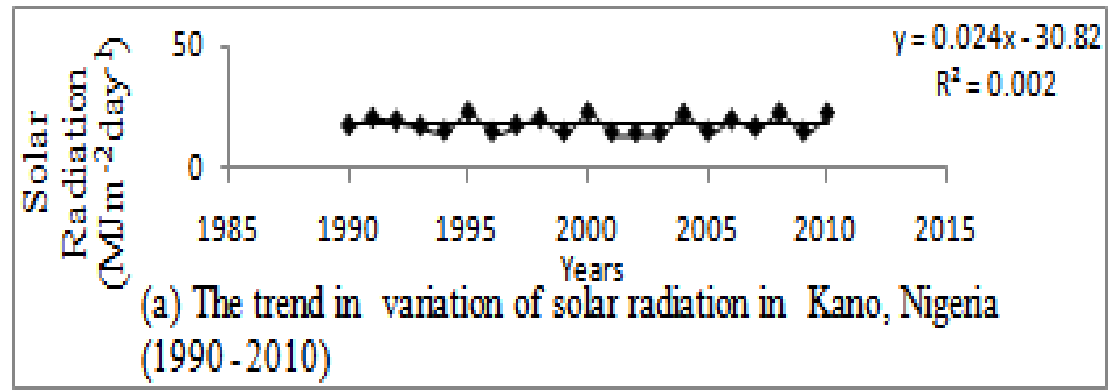



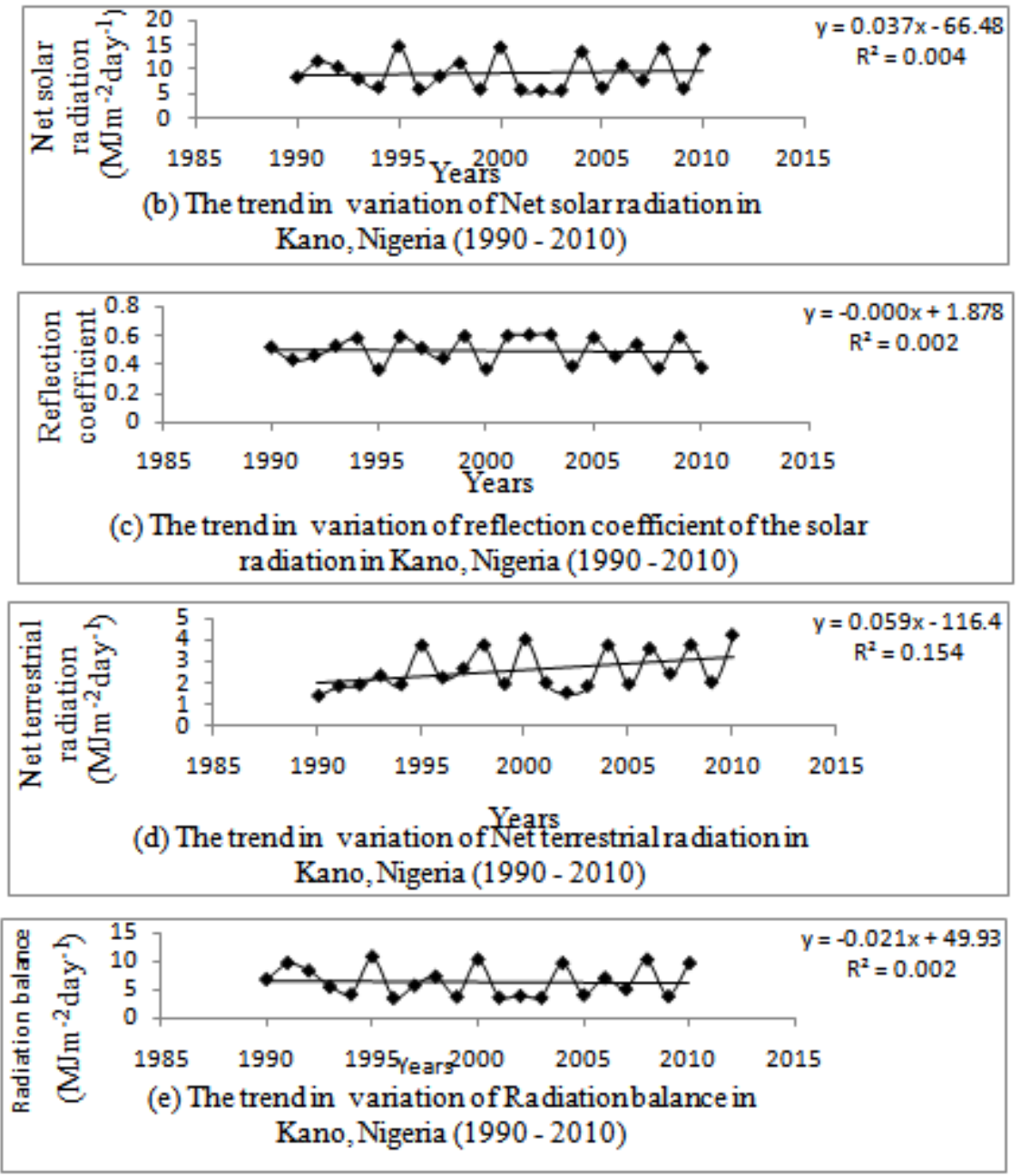

Fig. 4: Temporal variations of solar radiation parameters in Kano, Nigeria (1990 - 2010)

Table 1: Maximum and Minimum values of the solar energy parameters in some selected cities Nigeria $(1990-2010)$

\begin{tabular}{|c|c|c|c|c|c|c|c|c|c|c|c|c|c|c|c|c|c|c|c|c|}
\hline \multirow[t]{2}{*}{ location } & \multicolumn{4}{|c|}{$\mathrm{SR}\left(\mathrm{MJm}^{-2} \mathrm{day}^{-1}\right)$} & \multicolumn{4}{|c|}{$\operatorname{NSR}\left(\mathrm{MJm}^{-2} \mathrm{day}^{-1}\right)$} & \multicolumn{4}{|c|}{$\mathrm{RC}$ (or albino) (\%) } & \multicolumn{4}{|c|}{ NTR $\left(\mathrm{MJm}^{-2} \mathrm{day}^{-1}\right)$} & \multicolumn{4}{|c|}{$\mathrm{RB}\left(\mathrm{MJm}^{-2} \mathrm{day}^{-1}\right)$} \\
\hline & $\operatorname{Max}$ & $\mathrm{yr}$ & $\mathrm{Min}$ & $\mathrm{yr}$ & $\operatorname{Max}$ & yr & $\mathrm{Min}$ & $\mathrm{yr}$ & $\operatorname{Max}$ & yr & $\mathrm{Min}$ & $\mathrm{yr}$ & $\operatorname{Max}$ & yr & $\mathrm{Min}$ & $\mathrm{yr}$ & $\operatorname{Max}$ & $\mathrm{yr}$ & Min & $\mathrm{yr}$ \\
\hline $\mathrm{PH}$ & 21.43 & 1999 & 13.08 & 1991 & 12.78 & 1999 & 4.76 & 1991 & 64.00 & 1991 & 40.00 & 1999 & 3.29 & 1995 & 1.30 & 2002 & 9.69 & 2003 & 3.63 & 2002 \\
\hline \begin{tabular}{|l|} 
Enugu \\
\end{tabular} & 22.70 & 2000 & 12.69 & 2010 & 14.32 & 2000 & 4.47 & 2010 & 64.00 & 1996 & 37.00 & 2000 & 7.17 & 2000 & 2.47 & 1996 & 4.26 & 2003 & 1.82 & 2010 \\
\hline Maude & 22.87 & 2003 & 12.78 & 1995 & 14.77 & 1992 & 1.34 & 1995 & 64.00 & 1995 & 36.00 & 1992 & 5.01 & 1994 & 1.34 & 1995 & 10.95 & 1992 & 2.59 & 1993 \\
\hline Kano & 22.91 & 1995 & 14.20 & 2002 & 14.67 & 1995 & 5.63 & 2002 & 60.00 & 2002 & 36.00 & 1995 & 4.25 & 2010 & 1.40 & 1990 & 10.91 & 1995 & 3.72 & 1996 \\
\hline
\end{tabular}

$\mathrm{PH}=$ Port Harcourt; Max = Maximum value; Min = minimum value and $\mathrm{yr}=$ year of occurrence

It could be observed from Figure 1 that the temporal variations of the SR and NSR over the study period in Port Harcourt are positive, but with a very small coefficients of variations $\left(\mathrm{R}^{2}=0.55 \%\right.$ and $0.44 \%$ respectively). The maximum value of NSR (12.78 $\mathrm{MJm}^{-2} \mathrm{day}^{-1}$ ) was obtained in 1999 , (with the corresponding maximum albedo value of 64\%), while the minimum value of NSR (4.76 $\mathrm{MJm}^{-2} \mathrm{day}^{-1}$ ) was obtained in 1991 when the minimum albedo of $40 \%$ was obtained (Table 1). Thus, the albedo varies in opposite sense to the SR and NSR.

Table 1 also shows that maximum NTR $\left(3.29 \mathrm{MJm}^{-2} \mathrm{day}^{-1}\right)$ occurred in 1995 , with the minimum value of about $1.30 \mathrm{MJm}^{-2}$ day $^{-1}$ occurring in 2002. Thus, it could be said that maximum radiative heating and minimum radiative cooling were obtained 1995 and 2002 respectively. This minimum radiative cooling in 2002 
corresponded with the minimum RB $\left(9.69 \mathrm{MJm}^{-2} \mathrm{day}^{-1}\right)$ for Port Harcourt during the study period. Furthermore, from the equation of the curve (Fig. 1e), it is obvious that the trend in the variation of RB is negative, implying a decrease in radiation energy balance in Port Harcourt during the study period. This could be possible due to the increase in the solar reflective coefficient (albedo) of the atmosphere. This increase in the planetary albedo could be due to the location of Port Harcourt in a tropical rain forest zone, its industrial air emissions and its proximity to the Atlantic Ocean, thus, the influence of the vegetative canopies, industrial smoke and gas flares and ocean surface may account for the low NTR.

Figures $2 \mathrm{a}$-e show respectively the temporal variations of RS,NRS, NTR, RC and RB in Enugu over the period under study. The year 2000 was marked with a very high SR and NSR reaching the surface. That implied a very low reflected radiation, hence low albedo. And because a large amount of short wave would have been absorbed by the Earth, a large amount of outgoing long wave radiation, OLR NTR was remitted as NTR. Hence, in the year 2000, the minimum albedo and the maximum NTR were about $37 \%$ and $7.17 \mathrm{MJm}^{-2} \mathrm{day}^{-1}$ respectively (Table 1). However, the maximum RB $\left(1.82 \mathrm{MJm}^{-2} \mathrm{day}^{-1}\right)$. was obtained in 2010 when the NSR had the least value. It is important to note here that the RB has the same trend in variation with other parameters which on the other hand have opposite trend with the albedo. The low albedo could be as a result of the location of Enugu in Guinea savannah with tall grasses and few tall trees, hence few vegetative canopies that could have caused reflection of the SR. Secondly, the topography of the area with many hills flanking the town could not have allowed thick rain clouds that could have enhanced the reflection of SR.

Considering the Makurdi station, the lowest insolation obtained in 1995 brought about a corresponding least net long wave radiation or net terrestrial radiation (NTR) of about $1.34 \mathrm{MJm}^{-2} \mathrm{day}^{-1}$ emitted from the Earth's surface (Fig. 3d), whereas in 1994, when the albedo was very small, the highest amount $\left(5.00 \mathrm{MJm}^{-2} \mathrm{day}^{-}\right.$ ${ }^{1}$ ) of NTR was emitted from the Earth's surface. This implies that in 1994, there could have been more evapotranspiration or loss of moisture and high humidity due to high emission of NTR from the Earth's surface. This condition could have affected humans and crops adversely. Thus, the years 1994 and 1995 experienced very anomalous NTR in the area. This result agrees with [12], who observed among other things that Sudan and Sahel Savannah had strong negative vegetative greenness anomalies in the years 1994 and 1995.

The variation in RB over Makurdi area within the period under study portrays a positive trend with a gradient of 0.16 (Fig. 3e). However, the percentage of the variation is also negligibly small $\left(\mathrm{R}^{2}=0.16 \%\right)$, showing that the RB has been constant in the last two decades in the area. However, it could be observed that the highest radiation balance $\left(10.95 \mathrm{MJm}^{-2} \mathrm{day}^{-1}\right)$ was obtained in 1992 , with the lowest RB of about $2.59 \mathrm{MJm}$ ${ }^{2}$ day $^{-1}$ obtained in the year 1993. This could be due to an increase in greenhouse gases such as Carbon dioxide over the period, thereby perturbing the radiation balance ([13]). This is evident in Figure $3 \mathrm{~d}$ where the NTR has a high value of about $5.01 \mathrm{MJm}^{-2}$ day $^{-1}$ in 1994.

Figure 4 shows the temporal variations of solar radiation parameters in Kano, Nigeria $(1990-2010)$. The maximum NSR $\left(14.67 \mathrm{MJm}^{-2} \mathrm{day}^{-1}\right)$ was obtained in 1995, while the minimum NSR $\left(5.63 \mathrm{MJm}^{-2} \mathrm{day}^{-1}\right)$ was $^{-1}$ obtained in 2002 (Table1). It is interesting to note that the year 2002 of minimum NSR corresponded with the year of maximum albedo (60\%), while the year of maximum NSR (1995) corresponded with the year of minimum albedo (36\%). This corresponded with the maximum radiation balance of $10.91 \mathrm{MJm}^{-2} \mathrm{day}^{-1}$. Observation from Table 1 shows that among all the locations considered, the least albedo was obtained in Kano. This could be due to its Sahelian characteristics of mainly grass land and little or no vegetative canopies and rain clouds that could enhance the reflectivity of solar radiation. Consequently, the amount of solar radiation reaching the surface was maximum with SR as $22.91 \mathrm{MJm}^{-2}$ day $^{-1}$ (Table 1).

It could be observed that in all the locations, the amount of solar radiation reflected into space (albedo) is generally high, with the maximum values ranging from 60 to 64\%. In addition, it could be observed that, the least radiation balance was obtained in Enugu (Table 1).

\section{Conclusion}

The trend in radiation balance curves shows that:

- The Albedo was generally high (60 to 64\%), in all the locations considered, implying that majority of the solar radiation in these locations did not reach the surface.

- However, there are increases in the radiation balance in Port Harcourt and Makurdi locations, whereas in Enugu and Kano, the curves indicate negative or decrease in radiation balance. This implies that there is a balance in solar energy radiation budget that could enhance solar energy technologies in Port Harcourt and Makurdi towns.

\section{Acknowledgement}

Thanks to the International Institute for Tropical Agriculture (IITA) Ibadan, Nigeria for providing the data set used in this work 


\section{References}

[1]. Ezenekwe, L.N; Ezemonye, M.N and Emeribe C.N. (2013): Modeling the temporal patterns of short wave and long wave radiations over Sudan and Sahel Savannah. Sacha Journal of Environmental Studies, 3:34-44.

[2]. Ibeh, G. F; Eke V.O.C and Isikwue B.C. (2012): Theoritical and Artificial Neural Net work computation and Analysis of global solar radiation at Enugu with atmospheric parameter Journal of Natural Sciences Research 2(10): 2012.

[3]. Isikwue, B. C.; Amah, A. N. and Agada, P. O.(2012a): Empirical Model for the Estimation of Global Solar Radiation in Makurdi, Nigeria, Global Journal of Science frontier Research Physics Space Science (USA), 12 (1):58 - 61

[4]. Isikwue, B. C., Odiaka, C. H. and Utah, E. U. (2012b): Estimation of the diffuse fraction of Solar Radiation for Makurdi, Nigeria. International Journal of Science and Advanced Technology 2(2): 1- 4.

[5]. Isikwue, B. C., Audu, M. O. and Utah, E. U. (2012 c): Estimation of the diffuse fraction of solar radiation for Makurdi, Nigeria. International Journal of Science and Advanced Technology 2 (2): 1-10

[6]. Ogolo, E.O; Falodun, S.E; Oluyanmo S.S and Nymhas, E. (2009): Analysis of data on net long wave and Global radiation during a transition period in a tropical station in Southwest Nigeria. Pacific Journal of Science and Technology, 10; $584-$ 591.

[7]. Babatunde, E.B; Falaiye, O.A and Uhuegbu, C.C (2005): Simulated reflected SW - radiation and its characteristics variation at Ilorin, Nigeria. Nigerian Journal of Physics. 17: 193 - 201

[8]. Akpabio, L.E. and Etuk , S.E.(2003): Relationship between Global Solar Radiation and Sunshine Duration for Onne, Nigeria, Turkish Journal of Physics, 27, 161-167.

[9]. FAO (Food and Agricultural Organization) (1998): Irrigation and Drainage Paper 56, Italy, Rome

[10]. Slaviša Trajković and Svetlana Živković (2009): Effect of actual vapor pressure on estimating evapotranspiration at Serbia. Architecture and Civil Engineering 7 (2): 171 - 178.

[11]. Allen, R.G; Pereira, L.S.; Raes, D. and Smith, M. (1998): Crop Evapotranspiration. Guidelines for computing crop water requirements. (FAO) Irrigation and Drainage Paper No. 47, Food and Agricultural Organization of United Nations.

[12]. Aweda, E. D. and Adeyewa Z. D (2011): Inter annual variation of vegetation anomaly over Nigeria using satellite-derived index. Advances in Applied Science Research, 2011, (3): 468-475.

[13]. Ramanathan, V. (1987): The role of Earth radiation budget studies in climate and general calculations research. Geophysics Research, 92; $475-495$ 